\title{
Using dialogue features to predict trouble during collaborative learning
}

\author{
Bradley A. Goodman - Frank N. Linton • Robert D. \\ Gaimari · Janet M. Hitzeman • Helen J. Ross • \\ Guido Zarrella
}

The MITRE Corporation, 202 Burlington Road, M/S K302, Bedford, MA 01730 USA.

E-mails:\{bgoodman, linton, rgaimari,jhitz, hross, jzarrella\}@mitre.org

Published online: 19 April 2006

(C) Springer Science+Business Media, Inc. 2006

Errors introduced by the publisher occurred in the above-mentioned article which was published in User Modeling and User-Adapted Interaction 15(1-2): 85-134 (DOI 10.1007/ s11257-004-5269-x). On page 97, Figure 6 should appear as shown below. The second to the last paragraph of Section 5.2 on page 124 should be changed to the one below. Lastly, the vitae for Frank Linton and Janet Hitzeman on pages 133 and 134 should be as listed below.

One general issue arose with our implementation. Pierce often interrupted too far past when a problem surfaced to be helpful. One could address this difficulty by lowering the activation threshold for the underlying rule. Setting the threshold too low, as shown above, can result in too many interruptions, an equally undesired outcome. While fine-tuning of Pierce's rules

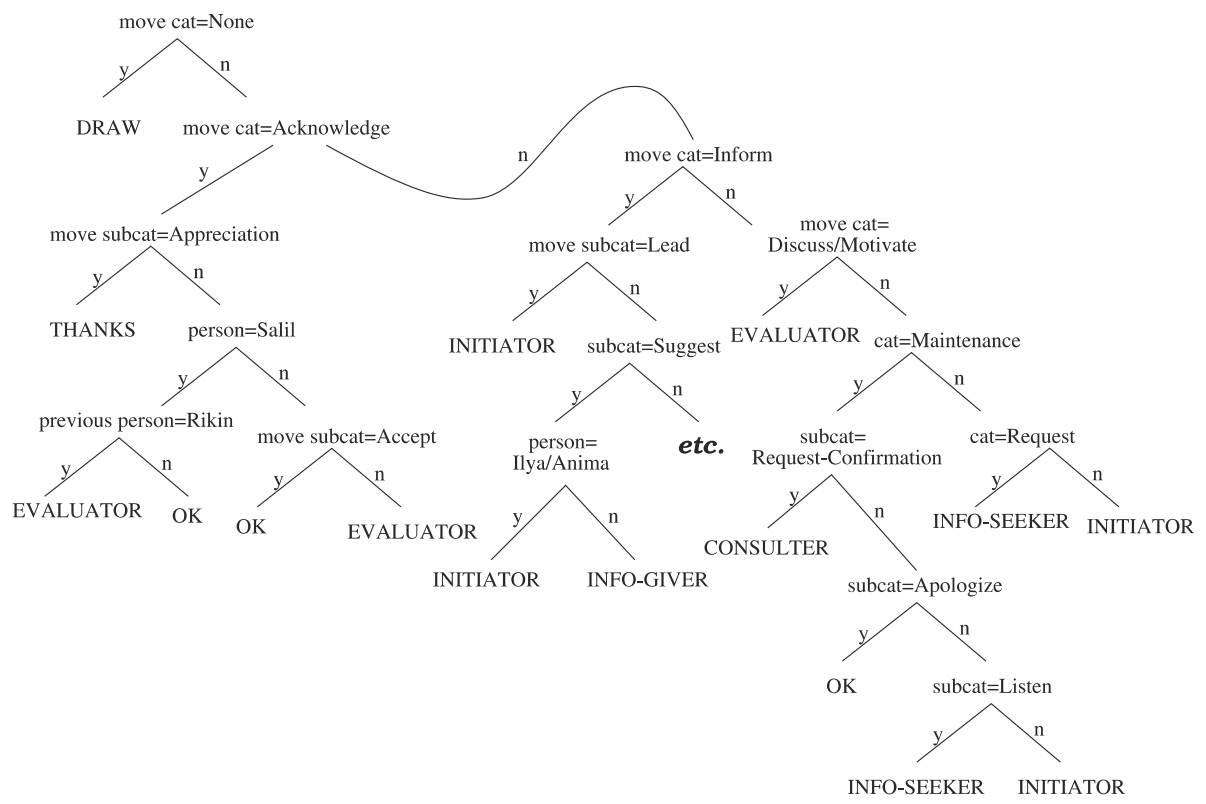

Fig. 6 A partial CART model. 
and thresholds helped, a more in-depth natural language analysis of the student dialogue could lead to better interventions by a peer agent.

\section{Dr. Frank Linton}

The MITRE Corporation, 7515 Colshire Drive, McLean, VA 22102, USA

Dr. Linton is a Lead Artificial Intelligence Engineer at the MITRE Corporation. He received his B.A. in Adult Training and Development from the University of Massachusetts, his Ed. M. in Educational Technology from Harvard University, and his Ed. D. in Artificial Intelligence in Education from the University of Massachusetts. Dr. Linton draws on advanced information system technologies to enhance the instructional capabilities of computer mediated learning, including intelligent tutoring systems, collaborative learning environments, and tools to support informal workplace learning. He has also performed research at US WEST Advanced Technologies and IBM T.J. Watson Laboratories.

\section{Dr. Janet Hitzeman}

The MITRE Corporation, 202 Burlington Road K309, Bedford, MA 01730, USA

Dr. Hitzeman is a Senior Artificial Intelligence Engineer at the MITRE Corporation. She received a B.S. degree in Mathematics and Computer Science at the University of California at Davis, an M.S. degree in Computer Science at the University of Southern California, and Ph.D. in Linguistics and Computer Science at the University of Rochester. Dr. Hitzeman worked at Hughes Aircraft and Kodak, and was also a research fellow at the University of Edinburgh. Her research focused on anaphoric reference, the automatic recognition of text structure and temporal expressions, the use of linguistic information to improve intonation in speech synthesis, and currently on information extraction. 